\title{
Adhesion of Clay Based Paint Coatings on Wood and Glass Substrates
}

\author{
*Timothée NSONGO ${ }^{1,2,3}$, Hilaire ELENGA ${ }^{2,3}$, Bernard MABIALA ${ }^{5}$,David BILEMBI ${ }^{4}$, \\ Ferland NGORO ELENGA ${ }^{1,3}$ \\ ${ }^{1}$ Groupe de Recherches sur les Propriétés Physico - Chimiques et Minérales des Matériaux Université \\ Marien NGOUABI, Brazzaville, CONGO \\ ${ }^{2}$ Centre de Recherches Géologiques et Minières, Brazzaville, CONGO \\ ${ }^{3}$ Faculté des Sciences et Techniques, Université Marien NGOUABI, B.P. 69 Brazzaville, CONGO. \\ ${ }^{4}$ Ecole Nationale Supérieure Polytechnique, Université Marien NGOUABI, Brazzaville, CONGO \\ ${ }^{5}$ Laboratoire Mécanique, Energétique et Ingénierie, Ecole Nationale Supérieure Polytechnique, \\ Université Marien NGOUABI, Brazzaville, CONGO
}

\begin{abstract}
The clay based paint coating was prepared both on a wood and a flat of glass substrates in order to study the adhesion. The scratch test technique associated to the acoustic emission was used to determine adhesion although the critical load which was taken as adhesion measurement. The critical load, mode of coatings removal and acoustic signal are discussed. It is found that the combination of acoustic signal and microscopic observations can indicate whether failure occurs following a cohesive or an adhesive mode. It also found that the critical load is determined by the appears of periodic patterns, this result was found to be in agreement with those obtained by others authors.
\end{abstract}

Keywords: Adhesion, coating, paint, glass substrate, wood substrate, scratch test.

\section{INTRODUCTION}

In the field of protective coatings, the scratch test is being used more and more to evaluate the adhesion ${ }^{[1,2,3,4,5]}$. The test consists in deforming the coating-substrate interface by drawing an indenter. The mechanical resistance of the interface is characterized by a critical load which the minimum load at which damage by lack of adhesion can be observed. The scratch test was widely used for metallic materials and the observed results have demonstrated that the critical load can be used as a representative of adhesion measurement ${ }^{[6,7,8,9]}$.

The objectives of this work were to establish the failure model of the paint coating as a non metallic material on polished wood and glass substrate to define the critical load for the given coating/substrate system and to analyze the acoustic emission signal caused by detachment of coating.

\section{EXPERIMENTAL DETAILS}

The substrates studied in this work were a plate of wood and glass with rectangular form $(2 \mathrm{~cm} \times 1 \mathrm{~cm})$ $2 \mathrm{~mm}$ thick. The wood substrate was given a final polish and cleaned with an flow of air. The glass substrate were cleaned in ultrasonic baths of acetone and washed in distilled water.

The scratch equipment was fitted with an acoustic signal detector. It registered the signal emitted in the range centered on $50 \mathrm{KHz}$. The digital microscope was used for the scratch observations.

\section{RESULTS AND DISCUSSION}

\subsection{Acoustic Signal}

\subsubsection{Clay Based Paint Coatings on Glass Substrate}

Figure1 shows records obtained from a paint layer on a glass substrate. The results show peaks painting. There in no particular peak, which means that there is no plastic deformation of the glass substrate. 


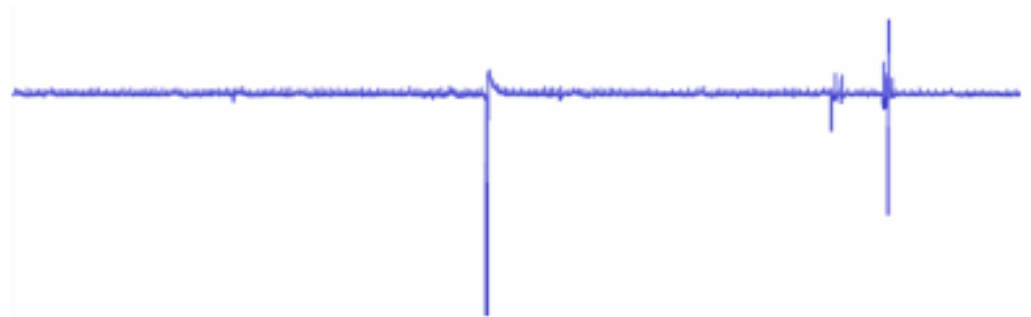

a)

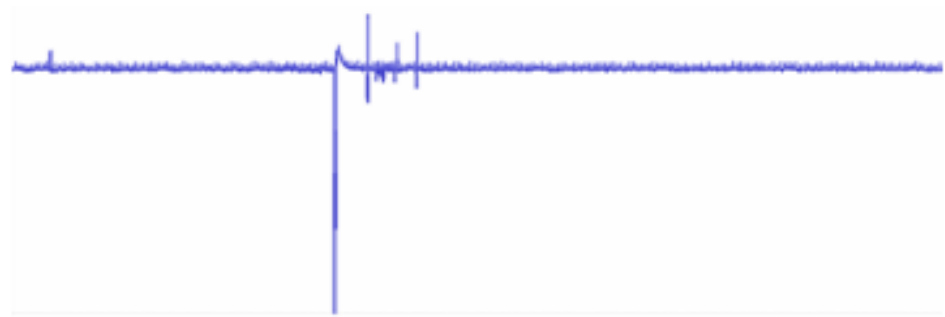

b)

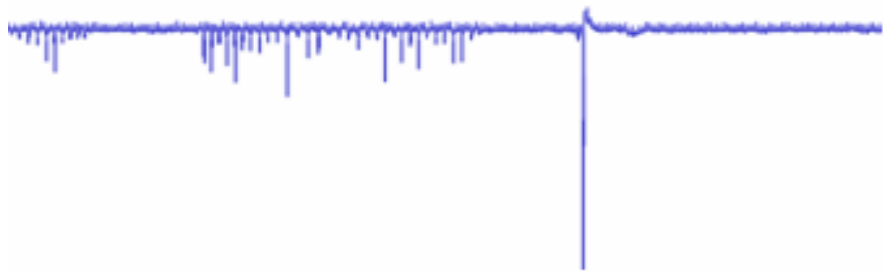

c)

Figure1. Acoustic emission as a function of the load applied on glass substrate coated with a paint layer:a) $m=$ $5 \mathrm{~g}$; $b) m=7 \mathrm{~g}$; $c) m=10 \mathrm{~g}$

\subsubsection{Clay Based Paint Coatings on Wood Substrate}

The onset of coating signal is in general accompanied by a marked increase in the acoustic signal.

The obtained acoustic signal recorded is represented on the figure 2 for $2 \mathrm{~g}, 4 \mathrm{~g}$ and $5 \mathrm{~g}$. The damage can be seen at $4 \mathrm{~g}$ with the apparition of additional peaks.

Figure 2 a) shows a signal which can be very weak when the coating loss is limited. Signals also seem to be related to cohesive damage in the coating. Thus as a general rule the correlation between acoustic signal and the damage to the sample should always be confirmed by microscopy examination.

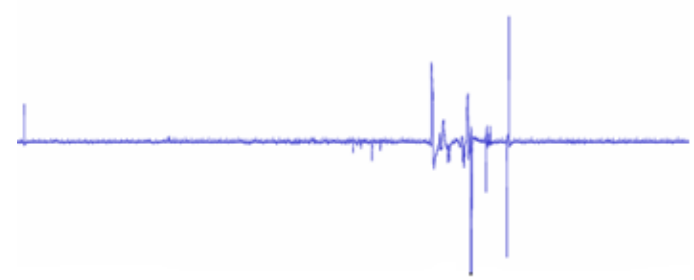

a)

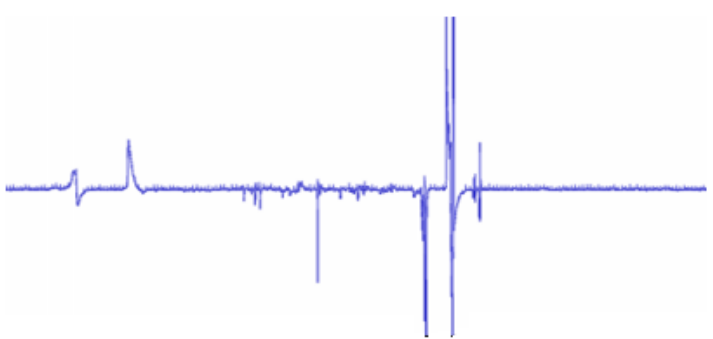

b) 


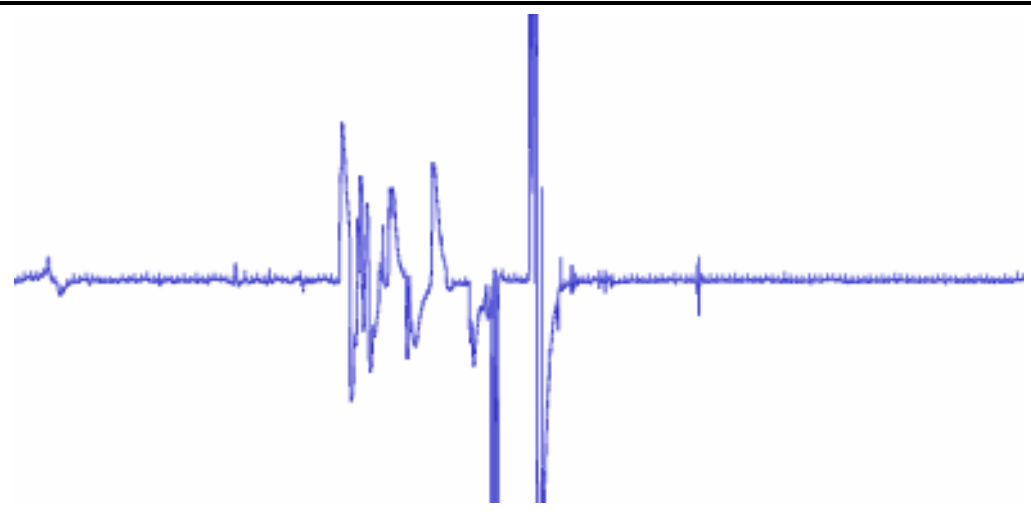

c)

Figure2. Acoustic emission signal as a function of the load applied to a glass substrate coated with a paint layer: a) $m=2 \mathrm{~g}$;b) $m=4 \mathrm{~g}$; c) $m=5 \mathrm{~g}$

\subsection{Scratch Digital Microscopic Observations}

Optical micrographs of typical failure mode of paints coatings are illustrated in figure $n^{\circ} 3: a$ ),b) and c)

When the propagation of the de-adhesion is stopped, acohesive crack which is perpendicular to the direction of the moving stylus is generated at the boundary between the detached and the undetached surfaces. Finally when the stylus moves over the detached surface, this process is repeated. Figure 3a) is micrograph illustrating a periodical pattern formed by these cohesive cracks.

At the load about $5 \mathrm{~g}$, the track is regular and rectilinear with a little period damage. This is confirmed the acoustic results.
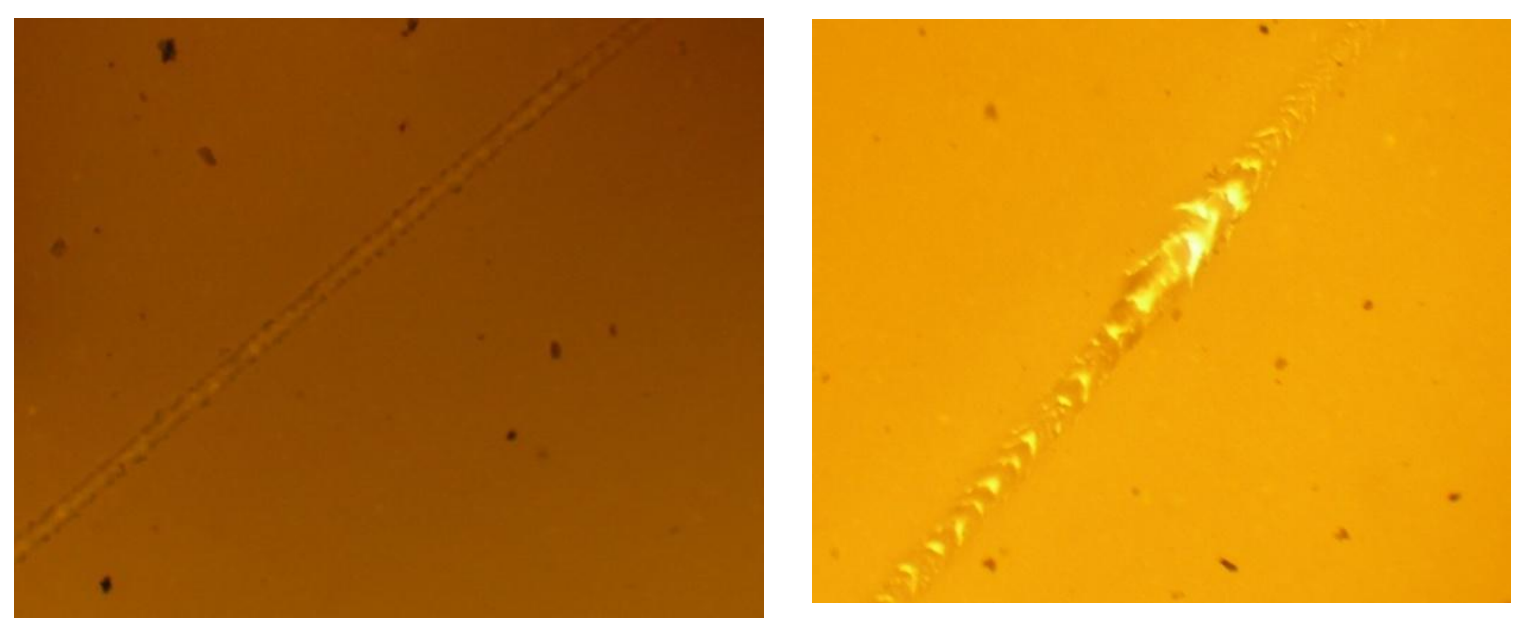

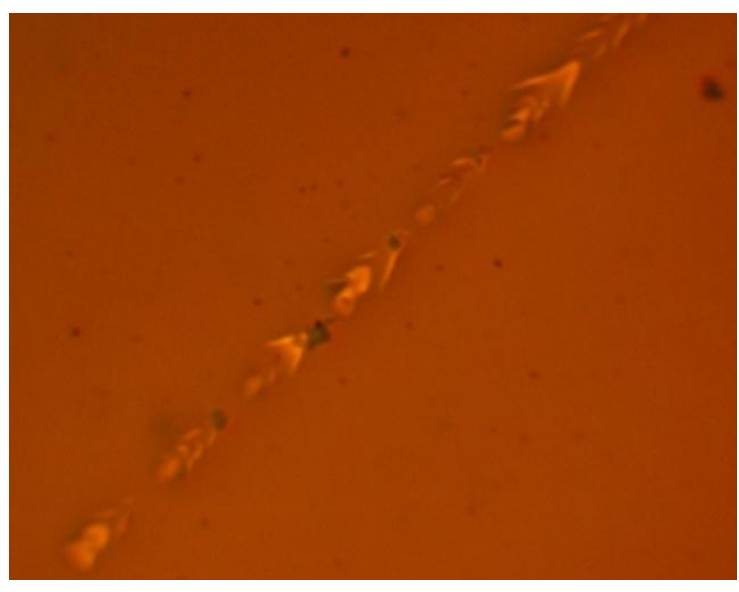

a)

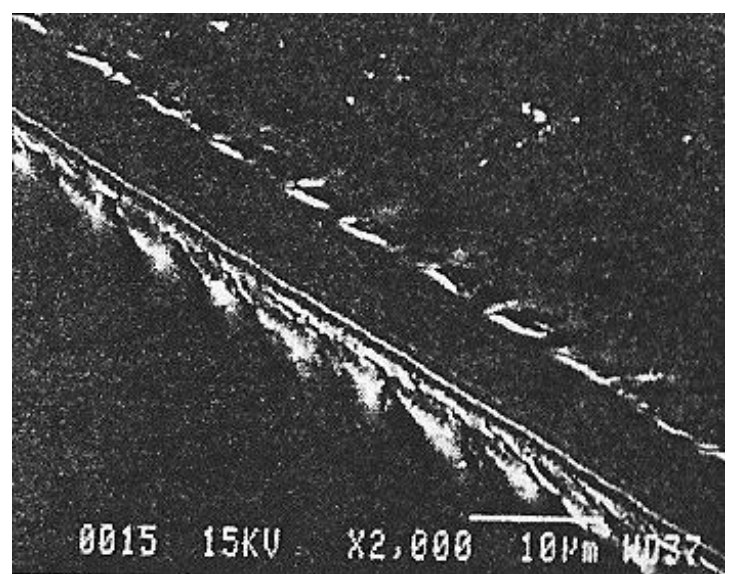

b)

Figure3. Optical micrographs of typical failure mode of paints coatings on glass substrate:

a) Scratch track at 5g.; b) scratch track at $7 g$ c);scratch track at $10 g$; d) scratch track Ref. [ 9 ] 
Butler and al. ${ }^{[6]}$ found that the plastic deformation begin first in the coating if it is thick and soft. Breaking the adhesion at the interface would happen then. In contrast, in the case of a hard substrate on a soft surface, it could produce a plastic deformation of the substrate.

In adhesion scratch testing, the mode of the coating failure appears to vary according to the nature of both substrate and the coating.

The number and the positions of the cracks coincide with the acoustic signal peaks. This indicates that each acoustic signal peak is due to an individual crack formation. The crack formation must have been followed by increase in acoustic signals, i.e. by the formation of one peak in the signals.

The obtained results are very similar than those published by the authors [9]

\section{Conclusion}

The scratch test were applied on paint coating prepared both on wood and glass substrates, a very typical period patterns were obtained .Theses results have been found to confirm acoustic analysis. This result was found to be in agreement with those obtained by other authors.

The scratch test were applied both on wood and glass substrate, a very typical period patterns were obtained .Theses results were found to confirm acoustic analysis and to be in agreement with those obtained by other authors ${ }^{[3,4]}$.

We were able to determine the critical load characteristic measure of adherence to the paint coating on the wood from the criterion of the plastic deformation of the substrate. However, we could evaluate the critical load on glass substrates coated with the paint. Similarly, we did not detect plastic deformation of the glass. It is possible to use the scratch test for adhesion testing but two parameters must be taken in account: the species of the wood and the humidity rate which can modify mechanical properties.

\section{REFERENCES}

[1] Gilbert GANGA, Hilaire ELENGA, Timothée NSONGO, Thomas Tamo TATSIETE, effect of environmental temperature and ph water on compressive strength of clay brick mixed wood chips mahogany based building materials, the sij transactions on industrial, financial \& business management (ifbm), vol. 2, no. 6, august 2014

[2] Gilbert GANGA, Timothée NSONGO, Gilbert GANGB, Bernard MABIALA, Thomas Tamo TATSIETE, NZONZOLO, effect of incorporation of chips and wood dust mahogany on mechanical and acoustic behavior of brick clay, journal of building construction and planning research, 2014, 2, 198-208

[3] T. NSONGO, adhesion characterization of titanium and titanium nitride thin coatings on metals using the scratch test, international journal of adhesion and adhesives (1995),15,191-196

[4] T. NSONGO, doctorate dissertation, university of aix marseille,1987 m.t. laugier, thin solid films, 984) 243-249

[5] Oh see GHEE, le vide, les couches minces, 220, jan/fév. 1984

[6] H.E. HINTERMANN, thin solid film, 84(1981) 215-243

[7] B. LEWIS AND J.C. ANDERSON. nucleation and growth of thin films, academic press, new york 1978.

[8] D.W. BUTLER, C.T.H. STODDART, P.R. STUART, journal of physics d,3 (1970) 877-883

[9] L.E. GOODMAN, A.S.M.E., journal of applied mechanics 29(1962) 515-522

[10] P. BENJAMIN, C.WEAVER, proceedings of royal society, series a. 254(1960) 163-176

[11] P. BENJAMIN, C. WEAVER, proceedings of royal society, series a252 (1959)418-430 